\title{
Constant diversification rates of endemic gastropods in ancient Lake Ohrid: ecosystem resilience likely buffers environmental fluctuations
}

\author{
K. Föller ${ }^{1, *}$, B. Stelbrink ${ }^{1, *}$, T. Hauffe ${ }^{1}$, C. Albrecht ${ }^{1}$, and T. Wilke ${ }^{1}$ \\ ${ }^{1}$ Department of Animal Ecology \& Systematics, Justus Liebig University Giessen, Heinrich-Buff-Ring 26-32, \\ 35392 Giessen, Germany \\ *These authors contributed equally to this work. \\ Correspondence to: B. Stelbrink (bjoern.stelbrink@allzool.bio.uni-giessen.de)
}

Received: 3 August 2015 - Published in Biogeosciences Discuss.: 31 August 2015

Revised: 23 November 2015 - Accepted: 24 November 2015 - Published: 10 December 2015

\begin{abstract}
Ancient lakes represent key ecosystems for endemic freshwater species. This high endemic biodiversity has been shown to be mainly the result of intra-lacustrine diversification. Whereas the principle role of this mode of diversification is generally acknowledged, actual diversification rates in ancient lakes remain little understood. At least four types are conceivable. Diversification rates may be constant over time, they may fluctuate, rates may be higher in the initial phase of diversification, or there may be a pronounced lag phase between colonization and subsequent diversification. As understanding the tempo of diversification in ancient lake environments may help reveal the underlying processes that drive speciation and extinction, we here use the Balkan Lake Ohrid as a model system and the largest species flock in the lake, the non-pyrgulinid Hydrobiidae, as a model taxon to study changes in diversification rates over time together with the respective drivers.

Based on phylogenetic, molecular-clock, lineage-throughtime plot, and diversification-rate analyses we found that this potentially monophyletic group is comparatively old and that it most likely evolved with a constant diversification rate. Preliminary data of the SCOPSCO (Scientific Collaboration On Past Speciation Conditions in Lake Ohrid) deepdrilling program do indicate signatures of severe environmental/climatic perturbations in Lake Ohrid. However, so far there is no evidence for the occurrence of catastrophic environmental events. We therefore propose that the constant diversification rate observed in endemic gastropods has been caused by two factors: (i) a potential lack of catastrophic environmental events in Lake Ohrid and/or (ii) a probably high ecosystem resilience, buffering environmental changes. Pa-
\end{abstract}

rameters potentially contributing to the lake's high ecosystem resilience are its distinct bathymetry, ongoing tectonic activities, and karst hydrology.

The current study not only contributes to one of the overall goals of the SCOPSCO deep-drilling program - inferring the driving forces for biotic evolution in Lake Ohrid. It might also enhance our understanding of how ecosystem resilience, in general, may promote relatively constant diversification rates in isolated ecosystems. However, we encourage future studies testing hypotheses about the lack of catastrophic events in Lake Ohrid. These studies should be based on high-resolution data for the entire geological history of the lake, and they should potentially involve information from the sediment fossil record, not only for gastropods but also for other groups with a high share of endemic taxa.

\section{Introduction}

Ancient lakes represent key ecosystems for the world's endemic freshwater biodiversity (Brooks, 1950; Martens et al., 1994; Martens, 1997; Rossiter and Kawanabe, 2000). Two hypotheses have been suggested for the underlying processes generating their often high levels of species richness. Originally, ancient lakes were considered to be evolutionary refugia that accumulate immigrating elements from extralimital areas during periods of environmental changes ("reservoir function"). Accordingly, distantly related "relic" species may have colonized a lake at different times and possibly from different geographic areas (e.g., Hauswald et al., 2008; Wilson et al., 2004). However, with the advance of 
molecular techniques, several researchers noted that many endemic species are considerably younger than the lake they inhabit. Hence, they suggested that the high endemic biodiversity in ancient lakes is predominantly a result of intralacustrine diversification ("cradle function") (e.g., Martens, 1997; Salzburger et al., 2005; Sherbakov, 1999).

Though the principle role of the cradle function is hardly disputed today, rates of diversification in ancient lakes remain little understood (e.g., Cristescu et al., 2010; Martens et al., 1994). As ancient lakes are considered to be comparatively stable systems (Martens, 1997), originally diversification rates (i.e., speciation minus extinction rates) were assumed to be constant over time. However, in the past decades, several factors, typically related to environmental change, have been proposed to alter the tempo of diversification in species flocks. The most renowned theory, punctuated equilibrium, suggests little net evolutionary change during periods of environmental stability (Gould and Eldredge, 1977; but see, e.g., Pennell et al., 2014; Van Bocxlaer et al., 2008). This equilibrium might be "punctuated" during phases of rapid environmental change. Another theory suggests that diversification rates can be higher in the initial phase of diversification (particularly in groups that diversify through an adaptive radiation) and may decline once niche spaces becomes successively occupied (e.g., Purvis et al., 2009; Schluter, 2000). This may happen after a lake first came into existence or after the occurrence of major environmental events such as volcanic ash deposits, severe lake-level drops, and desiccation or salinization events (Cristescu et al., 2010; Kroll et al., 2012; Salzburger et al., 2014). A forth theory proposes the opposite, i.e., the existence of a pronounced lag phase between colonization and onset of diversification (e.g., Cristescu et al., 2010).

However, these scenarios have rarely been tested in ancient lake environments due to the lack of appropriate candidate lakes and suitable model taxa. Criteria for a candidate lake would be a long and continuous existence, providing sufficient time for repetitive cladogenesis, as well as a good knowledge of its paleo-limnological history, enabling a link between geological and biotic evolution. The model taxon, in turn, should be monophyletic, permitting unbiased calculations of diversification rates; species rich, thus providing sufficient power for evolutionary analyses; and reasonably old, allowing for studying the effect of environmental changes on speciation rates over an extended period of time.

Of the few ancient lakes in the world, even fewer fulfil the above criteria. Some lakes, despite being old, have gone through a series of major environmental events, and the respective endemic species are often comparable young, as observed in Lake Malawi (e.g., Schultheiß et al., 2009, 2011) and Lake Titicaca (Kroll et al., 2012). Other lakes such as Lake Baikal (e.g., Ivanov et al., 2013) and Lake Tanganyika (e.g., Salzburger et al., 2014; Scholz et al., 2007) might be sufficiently old but lack a continuous paleo-limnological record. In fact, one of the very few ancient lakes enabling a link between geological and biotic evolution throughout its existence is the Balkan Lake Ohrid (Wagner et al., 2014). It is the oldest freshwater lake in Europe and perhaps the most speciose in the world when considering lake size (Albrecht and Wilke, 2008). Though the exact age of the lake remains controversially discussed, biological data suggest an age of no older than 2-3 million years (My) (e.g., Albrecht et al., 2006; Trajanovski et al., 2010; Wysocka et al., 2013). Newer sedimentological and seismological data obtained during the recently conducted SCOPSCO (Scientific Collaboration On Past Speciation Conditions in Lake Ohrid) deep-drilling project in Lake Ohrid revealed a minimum lake age (deep-water conditions) of ca. 1.2 My (Wagner et al., 2014), and an age of its oldest sediments of approximately 2.0 My (Lindhorst et al., 2015). This time frame of 1.2-2.0 My for the origin of extant Lake Ohrid is also considered in the current study.

Besides its relatively well characterized limnological history, Lake Ohrid also harbors a high number of endemic animal species. So far, at least 185 taxa have been described (Albrecht and Wilke, 2008; Pešić, 2015; Stocchino et al., 2013; Wysocka et al., 2013). In addition, there is a rich protist flora. Diatoms alone account for 789 taxa, with 117 of them being endemic to the lake (Levkov and Williams, 2012). Accordingly, a number of more than 300 endemic eukaryotic species for ancient Lake Ohrid is conceivable. The majority of the animal groups form relatively old species flocks in several higher taxa, including crustaceans (Wysocka et al., 2008, 2013, 2014), leeches (Trajanovski et al., 2010), and gastropods (Albrecht et al., 2006; Wilke et al., 2007, 2009). In fact, gastropods represent the most speciose animal group in Lake Ohrid, with 74 species described, 56 of which are endemic to the lake and its catchment (Albrecht and Wilke, 2008; Albrecht et al., 2009, 2014; Hauffe et al., 2011; Radoman, 1985). The largest share of this diversity is held by snails of the family Hydrobiidae (Caenogastropoda: Truncatelloidea), including 13 pyrgulinid and 27 other endemic species (Radoman, 1983). The latter group comprises the nominal genera Dolapia, Gocea, Lyhnidia, Ohrigocea, Ohridohauffenia, Ohridohoratia, Polinskiola, Pseudohoratia, Strugia, and Zaumia (see Fig. 1). Pending a formal classification of this potentially monophyletic taxon, it is henceforth called the "non-pyrgulinid Hydrobiidae". Given that this group probably represents the largest species flock in Lake Ohrid (see also Radoman, 1983), it appears to be a suitable candidate taxon to study speciation processes in this ancient lake.

Therefore, the major goal of the present study is to test for changes in diversification rates over time and to assess the underlying drivers. In order to achieve this objective, three specific goals are addressed.

i. Based on molecular-clock analyses, we estimate the age of the most recent common ancestor (MRCA) of this group as a baseline for our temporal studies. 


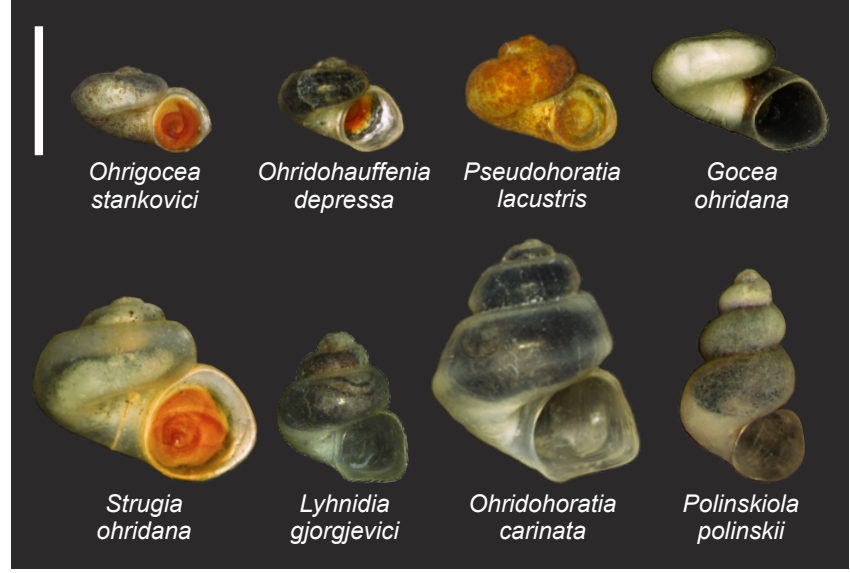

Figure 1. Selected representatives of genera belonging to the endemic non-pyrgulinid Hydrobiidae from Lake Ohrid. Scale bar: $1 \mathrm{~mm}$.

ii. Utilizing lineage-through-time (LTT) plot and diversification-rate analyses, hereinafter we assess changes in diversification rates over time.

iii. If deviations from a constant diversification model are inferred, we finally attempt to link environmental and climatic fluctuations derived from the SCOPSCO program to these biotic changes.

Given that Lake Ohrid has long been considered to be a relatively stable system with considerable ecosystem resilience (sensu Stankovic, 1960), our working hypothesis is that there are no significant changes in diversification rates over time in the lake's non-pyrgulinid Hydrobiidae.

The current study will complement paleontological evidence of evolutionary processes obtained from the SCOPSCO high-resolution sediment record and thus contribute to one of the overall goals of the deep-drilling program - inferring the driving forces for biotic evolution in this fascinating ancient lake. It might also enhance our general understanding of how environmental change alters the tempo of diversification in isolated ecosystems and how ecosystem stability may buffer such changes.

\section{Material and methods}

\subsection{Sampling}

Hydrobiid gastropods were collected during field trips to Lake Ohrid and other waterbodies in the Balkan region between 2003 and 2011 (Fig. 2; see Table 1 for details). The collection methods followed those described in Schreiber et al. (2012) and included hand collecting, snorkeling, sieving, and dredging from small boats or the research vessel of the Hydrobiological Institute Ohrid. Samples were preserved in

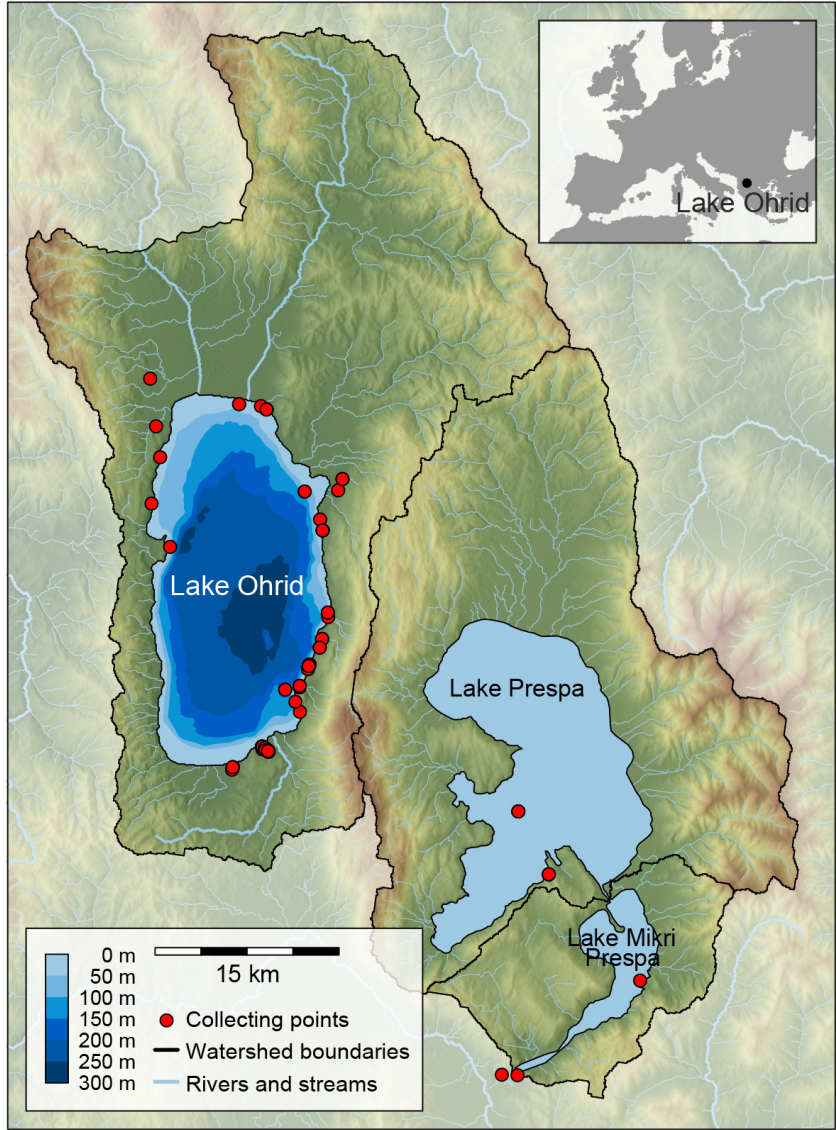

Figure 2. Sampling sites for non-pyrgulinid Hydrobiidae in lakes Ohrid, Prespa, and Mikri Prespa, and their watersheds.

$80 \%$ ethanol and determined in the laboratory to species level based on Radoman (1983).

\subsection{DNA isolation, PCR amplification, and DNA sequencing}

Genomic DNA was isolated from whole specimens using the CTAB protocol described in Wilke et al. (2006). Voucher specimens and digital images were deposited in the University of Giessen Systematics and Biodiversity collection (UGSB). Fragments of the mitochondrial genes for cytochrome oxidase c subunit I (COI) and large subunit rRNA (LSU rRNA or 16S rRNA) were amplified using the universal primers LCO1490 (Folmer et al., 1994) and COR722b (Wilke and Davis, 2000) as well as 16Sar-L and 16Sbr-H (Palumbi et al., 1991), respectively (for PCR conditions see Schreiber et al., 2012). Subsequent Sanger sequencing was conducted either on a Long Read IR2 4200 sequencer (LICOR, Lincoln, NE, USA) using the Thermo Sequenase fluorescent labelled primer cycle sequencing kit (Amersham Pharmacia Biotech, Piscataway, NJ, USA) or on a ABI 3730 XL sequencer (Life Technologies, Carlsbad, CA, USA) using the Big Dye Terminator Kit (Life Technologies, Carls- 


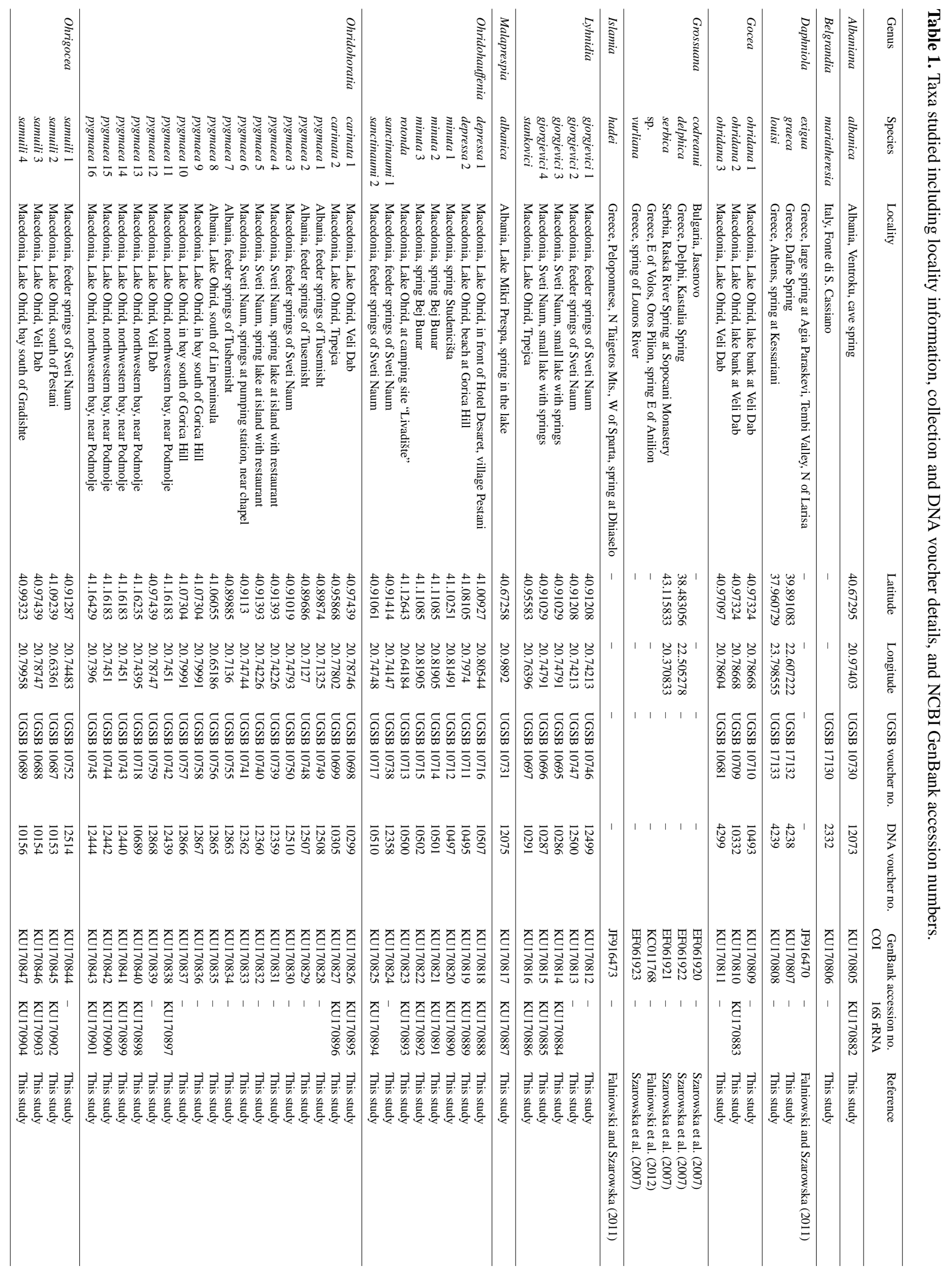




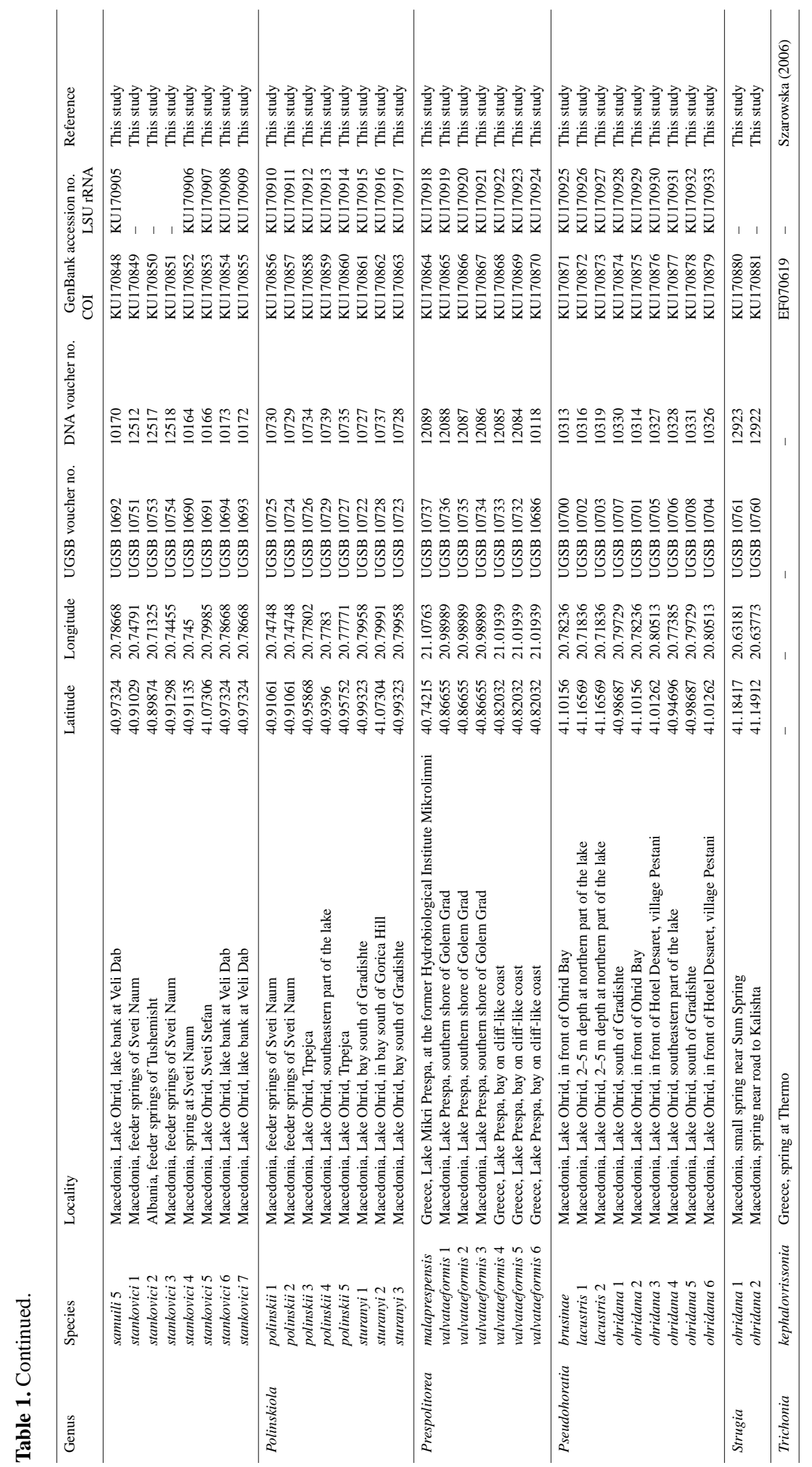


bad, CA, USA). In total, we sequenced 65 specimens of 17 nominal species of the endemic non-pyrgulinid Hydrobiidae. For comparison, we also analyzed 20 specimens of 15 closely related species occurring in lakes Prespa and Mikri Prespa as well as in surrounding waterbodies (Fig. 2; see Table 1 for locality details, UGSB collection numbers and GenBank accession numbers).

\subsection{Preliminary genetic analyses}

The protein-coding COI sequences were unambiguously aligned in BioEdit 7.0.9.0 (Hall, 1999), resulting in a final alignment of 638 base pairs (bp). The 16S rRNA sequences were aligned using the secondary structure model for the Hydrobiidae suggested by Wilke et al. (2013), resulting in a final alignment of $462 \mathrm{bp}$ including gaps (an internal fragment of $45 \mathrm{bp}$ was removed since no reliable alignment could be achieved for this region).

Prior to the phylogenetic analyses, our data set of nonpyrgulinid Hydrobiidae was supplemented with sequences of closely related species. We first performed searches with BLASTN 2.2.32 (Zhang et al., 2000) against the National Center for Biotechnology Information (NCBI) nucleotide database as well as against the nucleotide database of the Wilke lab, which contains DNA information for more than 300 hydrobiid species. A preliminary phylogenetic analysis was conducted in order to identify the hydrobiid groups that are most closely related to our endemic non-pyrgulinid Hydrobiidae. These preliminary analyses (details not shown) indicated that endemic species from the sister lakes Prespa and Mikri Prespa (Fig. 2) as well as from other Balkan waterbodies are the closest relatives to the Ohrid taxa. These taxa were included in our final data set (see Table 1).

\subsection{Phylogenetic inference and molecular-clock analyses}

The main phylogenetic analyses using Bayesian inference were performed in BEAST v. 1.8.0 (Drummond and Rambaut, 2007). Best-fit substitution models were estimated using jModelTest 0.1.1 (Posada, 2008) based on the Akaike information criterion. The models suggested for the COI and 16S rRNA fragments were GTR $+\mathrm{I}+\Gamma$ and GTR $+\mathrm{I}$, respectively. We tested the COI data set for substitutional saturation using the test by Xia and Xie (2001) as implemented in DAMBE 5.0.23 (Xia and Xie, 2001). The value for the proportion of invariant sites $(\mathrm{Pinv}=0.46)$ was obtained from the jModelTest output. The observed saturation was significantly lower than the critical values $(p<0.001)$, suggesting that this partition can be used for further (molecular-clock) analyses. Note that we did not test for saturation in the $16 \mathrm{~S}$ data set as, within the family Hydrobiidae, the $16 \mathrm{~S}$ gene is more conservative than the COI gene (Wilke et al., 2001, 2013).
We first ran two unconstrained analyses in BEAST, one under the strict-clock and one under the relaxed-clock model, using relative rates for both partitions. These initial runs, however, revealed an extremely low effectivity sample size for the prior and posterior distributions, suggesting that the runs might have been over-parameterized due to the complex GTR + I $+\Gamma$ model (see, e.g., Grummer et al., 2014; Slager et al., 2014). Hence, the less complex HKY $+\mathrm{I}+\Gamma$ and HKY $+\mathrm{I}$ models were used for the final analyses for the COI and $16 \mathrm{~S}$ rRNA partitions, respectively.

For calibrating the molecular clock, an external trait-specific clock rate of $1.57 \pm 0.45 \% \mathrm{My}^{-1}$ for the $\mathrm{HKY}+\mathrm{I}+\Gamma$ model was utilized for the COI portion of our data set (Wilke et al., 2009). This rate was established for small, dioecious, subtropical or tropical Protostomia with a generation time of approximately 1 year - all of these criteria apply to our non-pyrgulinid Hydrobiidae.

The final analyses (two strict-clock and two relaxedclock runs) with a total of 85 sequences were run for 100000000 generations each, sampling every 5000 generations. The resulting $\log$ and tree files for each strict-clock and relaxed-clock run were combined using LogCombiner v. 1.8.0 (BEAST) with a $50 \%$ burn-in. The maximum clade credibility (MCC) tree was identified based on the posterior distribution (20000 trees). Information from the postburn-in posterior distribution including mean node ages and $95 \%$ highest posterior densities (HPDs) was summarized using TreeAnnotator v. 1.8.0 (BEAST; no additional burnin). A Bayes factor (BF) analysis of the likelihoods of both runs (strict-clock vs. relaxed-clock model) was performed in Tracer 1.5 (Rambaut and Drummond, 2007; 1000 bootstrap replicates) in order to determine the best-fitting clock model (see Newton and Raftery, 1994; Suchard et al., 2001).

The BF analysis, which compares the likelihoods of both BEAST runs (strict- vs. relaxed-clock model), showed a decisive support for the relaxed-clock model with a BF of 45.61 $\left(\ln P_{\text {relaxed }}=-5213.40 \mathrm{vs} . \ln P_{\text {strict }}=-5318.42\right)$.

\subsection{Lineage-through-time plot and diversification-rate analyses}

In a first explorative analysis, LTT plot analyses were conducted using the packages ape v. 3.3 (Paradis et al., 2004) and phytools v. 0.4-56 (Revell, 2012) for the R statistical environment 3.2.1 (R Core Team, 2015) in order to examine whether major deviations from a constant diversification rate can be directly observed over time. In this way, all but the endemic non-pyrgulinid Hydrobiidae from Lake Ohrid were pruned. In a second step, a LTT plot was generated for the MCC tree plus a $95 \%$ confidence interval based on the posterior distribution.

However, generating LTT plots and detecting changes in the slope is an explorative approach and might lead to misinterpretations (see Stadler, 2011). Therefore, potential shifts in diversification rates over time were analyzed using the $\mathrm{R}$ 
package TreePar v. 3.3 (Stadler, 2015) by testing a maximum of three shifts for 10 trees randomly sampled from the posterior distribution. This package implements a birth-deathshift model (Stadler, 2011), which allows changes in speciation and extinction rates along a phylogeny for a given time frame and for pre-defined time intervals. Shifts were analyzed along the pruned tree with default settings and a time interval of $0.1 \mathrm{My}$. The sampling fraction was set to $17 / 27=0.63$ according to the actual number of species included divided by the number of nominal species described. Results (log likelihoods of different runs, i.e., constant diversification rate vs. 1 shift, 1 shift vs. 2 shifts, and 2 shifts vs. 3 shifts) were compared by applying likelihood ratio tests in order to examine whether shifts in rates explain the tree significantly better than a constant diversification rate (indicated by $p$ values $>0.95$; see Stadler, 2011, 2015).

\section{Results}

\subsection{Phylogenetic inference and molecular-clock analyses}

The relaxed-clock MCC tree (Fig. 3) shows that the endemic non-pyrgulinid Hydrobiidae from Lake Ohrid likely form a monophyletic group (Bayesian posterior probability $(\mathrm{BPP})=0.87)$. The potential sister to the Lake Ohrid group is a monophyletic group containing endemic non-pyrgulinid Hydrobiidae species from its sister lakes, lakes Prespa and Mikri Prespa, and their catchments. The split from a MRCA for these two groups is supported by a BPP of 1.0. The closest relatives to the Ohrid/(Mikri) Prespa group are other Balkan hydrobiids $(\mathrm{BPP}=1.0)$ previously classified into the nominal subfamilies Belgrandiellinae, Belgrandiinae, and Horatiinae (see Wilke et al., 2014).

The molecular-clock analyses indicates an age for the MRCA of the endemic non-pyrgulinid Hydrobiidae from Lake Ohrid (i.e., the onset of diversification within this group) under the favored relaxed-clock model of 1.753.76 My (95\% HPD; see Fig. 3). Under the inferior strictclock model, the upper value is slightly lower at 1.75 $2.68 \mathrm{My}$.

\subsection{Diversification-rate analysis}

The $95 \%$ LTT plot does not suggest major deviations from a constant diversification rate (Fig. 4a). This finding is supported by the TreePar (birth-death-shift) diversification-rate analysis. Accordingly, the likelihood ratio tests suggest for 8 out of 10 random trees a constant rate over time. Only in two of the random trees is a single shift at an age of $0.1 \mathrm{My}$ detected (Fig. 4b and Table 2).

\section{Discussion}

\subsection{The Ohrid non-pyrgulinid Hydrobiidae: an old species flock}

Our phylogenetic analyses indicate that the non-pyrgulinid Hydrobiidae form a potential monophyletic, speciose, and endemic clade, and thus, by definition, represent a species flock (Greenwood et al., 1984; Schön and Martens, 2004). Therefore, in situ diversification appears to be a main process in this group. The latter conclusion even holds under the assumption of a non-monophyly of the Ohrid taxa.

The age estimates obtained from the molecular-clock analysis revealed that the Lake Ohrid flock potentially started to diversify before extant Lake Ohrid came into existence (i.e., in a pre-lake/paleo-lake phase or in other waterbodies of the Ohrid Graben system such as rivers or springs; see Figs. 3 and $4 \mathrm{a}$ ). In fact, karst springs have previously been proposed as potential ancestral habitats for other invertebrate flocks inhabiting Lake Ohrid such as the pulmonate snail genus Ancylus (Albrecht et al., 2006), leeches of the genus Dina (Trajanovski et al., 2010), and the isopod genus Proasellus (Kilikowska et al., 2013). This may also be the case for the species flock studied here, given that karst springs are the dominant habitat of its closest relatives outside lakes Ohrid, Prespa, and Mikri Prespa. However, testing this hypothesis is beyond the scope of the current study and probably would require a denser sampling, more precise limnological information about the early stage of Lake Ohrid, and more specific approaches such as the reconstruction of ancestral waterbodies as well as better calibration points for molecular-clock analyses.

\subsection{The Ohrid non-pyrgulinid Hydrobiidae: constant rate of diversification over time}

As mentioned in the Introduction, at least four modes of tempo of speciation in ancient lake species flocks are conceivable. Diversification rates may (1) be constant over time, (2) fluctuate ("punctuated equilibrium"), (3) be higher in the initial phase of diversification, or (4) show a pronounced lag phase between colonization and subsequent diversification.

As understanding the temporal frame of speciation in Lake Ohrid is of considerable importance for reaching one of the main goals of the Ohrid scientific deep-drilling program inferring the driving forces for biotic evolution - the second specific goal of the current study is to estimate diversification rates over time. Given that Lake Ohrid has long been regarded as a relatively stable system (Stankovic, 1960), our working hypothesis assumes no significant changes in diversification rates over time in the lake's non-pyrgulinid Hydrobiidae.

Interestingly, our LTT plot suggests that the species flock most likely evolved with a constant diversification rate. This finding is supported by our diversification-rate analysis, in- 


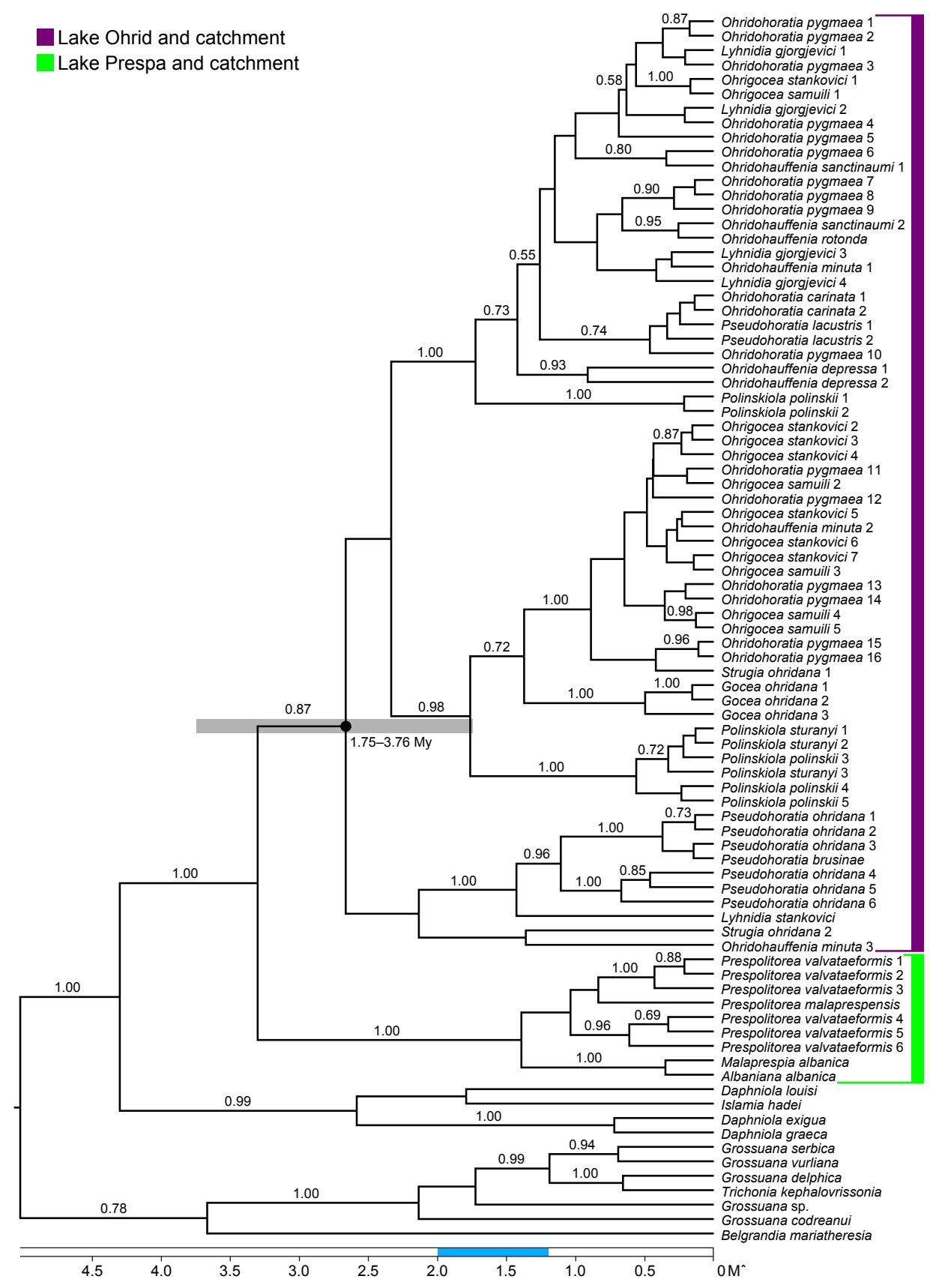

Figure 3. MCC tree based on a relaxed-clock BEAST analysis for non-pyrgulinid Hydrobiidae from the Balkans. Posterior probabilities $>0.5$ are shown at the respective branches. The grey bar indicates the $95 \%$ HPD for the age of the MRCA of the Ohrid endemics. The blue bar in the timescale ranging from 1.2 to $2.0 \mathrm{My}$ shows the assumed age of Lake Ohrid.

dicating a single recent shift (drop of rates) at $0.1 \mathrm{Ma}$ for 2 out of 10 random trees (i.e., a time frame in which incomplete lineage sorting may play a role; Fig. $4 \mathrm{~b}$ and Table 2). Therefore, our initial working hypothesis - a constant diversification rate - cannot be rejected. However, we cannot rule out a type II error here due to poorly resolved phylogenetic trees or insufficient sampling size. As for the quality of the phylogenetic tree used for the LTT plot and the subsequent diversification-rate analyses, our analyses, indeed, revealed some poorly supported (especially recent) nodes (Fig. 3). However, timetree studies are relatively robust against phylogenetic uncertainties (see, e.g., Morvan et al., 2013) as a poorly supported topology does not necessarily affect the timing of rapid speciation events (e.g., Pagel, 1999). We are therefore confident that the low BPP support of some nodes 


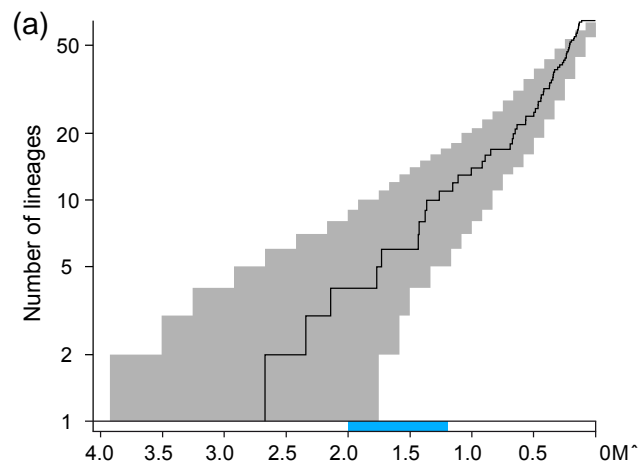

(b)

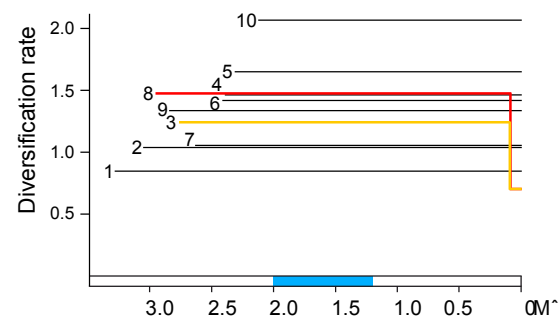

Figure 4. (a) LTT plot for the endemic non-pyrgulinid Hydrobiidae in Lake Ohrid. The plot is based on a relaxed-clock BEAST analysis, with the black line showing the BEAST MCC and the shaded area indicating the $95 \%$ confidence interval based on 20000 post-burn-in BEAST trees. The blue bar ranging from 1.2 to $2.0 \mathrm{My}$ shows the assumed age of Lake Ohrid. (b) Diversification rates obtained from the diversification-rate analyses (TreePar); trees with a single shift in diversification rates at $0.1 \mathrm{My}$ (trees nos. 3 and 8 ) are highlighted in red and yellow.

Table 2. Reduced output of the diversification-rate analyses (TreePar). $P$ values $>0.95$ indicate that a single shift in rates explains the tree significantly better than constant diversification rates, that two shifts explain the tree significantly better than a single shift, or that three shifts explain the tree significantly better than two shifts (see main text for details).

\begin{tabular}{|c|c|c|c|c|c|}
\hline $\begin{array}{r}\text { Random tree } \\
\text { no. }\end{array}$ & $\begin{array}{r}\text { Max. age } \\
\text { (My) }\end{array}$ & $\begin{array}{l}\text { Rate } \\
\text { shifts }\end{array}$ & Log likelihood & $\begin{array}{r}P \\
\text { value }\end{array}$ & $\begin{array}{l}\text { Shift } \\
\text { (Ma) }\end{array}$ \\
\hline \multirow[t]{3}{*}{1} & 3.29 & 0 vs. 1 & 45.882 vs. 42.043 & 0.947 & \\
\hline & & 1 vs. 2 & 42.043 vs. 38.749 & 0.914 & \\
\hline & & 2 vs. 3 & 38.749 vs. 37.060 & 0.663 & \\
\hline \multirow[t]{3}{*}{2} & 3.06 & 0 vs. 1 & 46.292 vs. 45.073 & 0.514 & \\
\hline & & 1 vs. 2 & 45.073 vs. 43.192 & 0.712 & \\
\hline & & 2 vs. 3 & 43.192 vs. 42.478 & 0.301 & \\
\hline \multirow[t]{3}{*}{3} & 2.77 & 0 vs. 1 & 36.879 vs. 32.362 & 0.971 & 1 shift: 0.1 \\
\hline & & 1 vs. 2 & 32.362 vs. 30.577 & 0.688 & \\
\hline & & 2 vs. 3 & 30.577 vs. 28.505 & 0.754 & \\
\hline \multirow[t]{3}{*}{4} & 2.40 & 0 vs. 1 & 28.083 vs. 26.171 & 0.712 & \\
\hline & & 1 vs. 2 & 26.171 vs. 25.507 & 0.278 & \\
\hline & & 2 vs. 3 & 25.507 vs. 23.337 & 0.773 & \\
\hline \multirow[t]{3}{*}{5} & 2.32 & 0 vs. 1 & 18.364 vs. 14.942 & 0.923 & \\
\hline & & 1 vs. 2 & 14.942 vs. 12.978 & 0.731 & \\
\hline & & 2 vs. 3 & 12.978 vs. 10.751 & 0.784 & \\
\hline \multirow[t]{3}{*}{6} & 2.42 & 0 vs. 1 & 31.850 vs. 29.342 & 0.829 & \\
\hline & & 1 vs. 2 & 29.342 vs. 27.932 & 0.580 & \\
\hline & & 2 vs. 3 & 27.932 vs. 26.219 & 0.670 & \\
\hline \multirow[t]{3}{*}{7} & 2.64 & 0 vs. 1 & 31.770 vs. 29.237 & 0.833 & \\
\hline & & 1 vs. 2 & 29.237 vs. 28.266 & 0.415 & \\
\hline & & 2 vs. 3 & 28.266 vs. 27.571 & 0.292 & \\
\hline \multirow[t]{3}{*}{8} & 2.96 & 0 vs. 1 & 34.733 vs. 30.793 & 0.951 & 1 shift: 0.1 \\
\hline & & 1 vs. 2 & 30.793 vs. 28.986 & 0.694 & \\
\hline & & 2 vs. 3 & 28.986 vs. 27.431 & 0.625 & \\
\hline \multirow[t]{3}{*}{9} & 2.85 & 0 vs. 1 & 34.152 vs. 31.644 & 0.829 & \\
\hline & & 1 vs. 2 & 31.644 vs. 29.433 & 0.781 & \\
\hline & & 2 vs. 3 & 29.433 vs. 27.109 & 0.801 & \\
\hline \multirow[t]{3}{*}{10} & 2.13 & 0 vs. 1 & 31.492 vs. 28.169 & 0.916 & \\
\hline & & 1 vs. 2 & 28.169 vs. 25.885 & 0.794 & \\
\hline & & 2 vs. 3 & 25.885 vs. 23.883 & 0.739 & \\
\hline
\end{tabular}


in our tree had no significant influence on the outcome of our hypothesis testing.

Moreover, we also think that our conclusions are not affected by a non-monophyly of the Ohrid group (see random tree no. 2) as the split between Prespa and Ohrid taxa is, in any event, older than $2 \mathrm{My}$ and thus does not affect intralacustrine diversification rates within the Lake Ohrid clade.

As for the sampling size (i.e., 17 out of 27 nominal species studied), the high diversity of evolutionary lineages found in our phylogenetic analyses indicates that our sampling design likely recovered most major evolutionary lineages within this group. Our sampling includes the majority of genera described except for Dolapia (which some authors included in the genus Ohrigocea) and Zaumia. We also included a variety of specimens collected at various types of habitats and type localities across the lake and its surroundings (see Fig. 2). Moreover, the diversification-rate analysis does account for incomplete sampling, and we did infer a single rate shift in two of the random trees tested in the present study. Thus, the method used seems to have enough power to detect deviations from a constant diversification rate in our data set.

\subsection{Ecosystem resilience of Lake Ohrid}

If we assume that the rate of diversification in the nonpyrgulinid Hydrobiidae from Lake Ohrid is constant, linking environmental/climatic fluctuations to changes in tempo of diversification becomes impossible (see specific goal iii).

However, an important question is whether a non-constant diversification rate could not be demonstrated because Lake Ohrid never experienced massive environmental and/or climatic changes or whether the lake has a high ecosystem resilience that might buffer such perturbations. Preliminary data of the SCOPSCO deep-drilling program based on core catcher data for the last $1.2 \mathrm{My}$ and high-resolution data for the last 640 thousand years (ky) so far do not indicate the occurrence of catastrophic environmental events (Francke et al., 2015; Wagner et al., 2014), i.e., events that lead to sudden drastic regime shifts (sensu Scheffer and Carpenter, 2003; Scheffer et al., 2001) and thus potentially to mass extinction. By comparison, such events have been observed in other ancient lakes, including Lake Titicaca (Kroll et al., 2012; Lavenu, 1992) and Lake Malawi (Cohen et al., 2007; Scholz et al., 2007; Schultheiß et al., 2009, 2011). We do, however, see signatures of severe environmental/climatic perturbations in Lake Ohrid, including significant lake-level drops (Lindhorst et al., 2010), volcanic ash deposits (Sulpizio et al., 2010; Wagner et al., 2014), and glacial-interglacial cycles (Lézine et al., 2010; Reed et al., 2010; Wagner et al., 2014).

Therefore, we think that the lack of changes in tempo of diversification of Lake Ohrid's non-pyrgulinid Hydrobiidae might potentially be a result of two factors: (i) either Lake Ohrid never experienced catastrophic environmental events that resulted in the extinction of all or most of its endemic taxa and thus caused a "reset" of diversification processes or (ii) Lake Ohrid possibly has a high ecosystem resilience that buffers environmental changes and potentially mitigates extinction events. Note that the two factors might not be mutually exclusive as it has been shown that a loss of resilience may set the scene for a catastrophic-event-induced switch to an alternative state (reviewed in Scheffer et al., 2001).

The second scenario is supported by the mollusk (Albrecht et al., 2010) and diatom fossil records (Cvetkovska et al., 2015; Jovanovska et al., 2015) for the past $\sim 100$ ky. For instance, the Campanian Ignimbrite Y5 tephra influx $39.6 \mathrm{ky}$ ago (see Leicher et al., 2015) altered the water chemistry of Lake Ohrid and increased the content of silica, which in turn amplified diatom growth rates. However, it did not cause severe changes in diatom community structures or even extinction events (Jovanovska et al., 2015).

The suggested high ecosystem resilience of Lake Ohrid might be sustained by several factors, including the lake's bathymetry (deep lake with steep flanks, allowing habitats to move vertically with lake-level changes; Lindhorst et al., 2010), ongoing moderate tectonic activities (compensating sedimentation; Hinderer and Einsele, 2001), and its peculiar limnology (the lake is fed by numerous karstic sublacustrine springs, locally buffering environmental changes; Matzinger et al., 2006).

Although we think that the patterns inferred from mtDNA sequencing data of extant taxa are highly informative, future analyses utilizing additional (nuclear) markers may help better resolve some of the basal relationships of Ohrid taxa. Moreover, the temporal resolution is still limited, the error rate for time estimates is relatively high, and some important processes such as extinction events are difficult to infer from extant organisms (see also Rabosky, 2010, for a discussion). Therefore, we encourage future paleontological studies on endemic species using the sediment cores gained during the SCOPSCO deep-drilling campaign. This concerns, for example, diatoms and ostracods. Moreover, besides the main core "DEEP", obtained from the deepest part of Lake Ohrid, several other cores were retrieved in shallower parts of Lake Ohrid. The latter appears to be relatively rich in mollusk fossils (see Wagner et al., 2014), which could potentially be used to directly study extinction and speciation events (for a proof of principle see Albrecht et al., 2010).

\section{Conclusions}

Our molecular-clock analyses indicate that the nonpyrgulinid Hydrobiidae of ancient Lake Ohrid represent an old endemic group, which is characterized by a constant rate of diversification. We propose that this constant rate has been caused by two factors: (i) a possible lack of catastrophic environmental events in Lake Ohrid and/or (ii) a high ecosystem resilience, buffering environmental changes. Parameters potentially contributing to Lake Ohrid's ecosystem resilience 
are its distinct bathymetry, ongoing tectonic activities, and karst hydrology. These findings are not only of interest for one of the overall goals of the SCOPSCO deep-drilling program - inferring the driving forces for biotic evolution in Lake Ohrid. They might also enhance our understanding of how ecosystem resilience, in general, may promote a relatively constant diversification in highly isolated ecosystems.

However, high-resolution sedimentological data are currently only available for the last $640 \mathrm{ky}$. Therefore, we encourage future studies specifically testing hypotheses about the lack of catastrophic events in Lake Ohrid based on highresolution data for the entire geological history of the lake, and potentially involving information from the sediment fossil record not only for gastropods but also for other groups with a high share of endemic taxa.

Author contributions. T. Wilke and C. Albrecht conceived the study. K. Föller and T. Hauffe collected and identified specimens. K. Föller performed lab work. K. Föller and B. Stelbrink performed the analyses. The manuscript was written by B. Stelbrink, T. Wilke, and K. Föller, with contributions from all co-authors. All authors gave final approval for publication.

Acknowledgements. We are very grateful to the colleagues of the Hydrobiological Institute Ohrid for their valuable support. D. Georgiev is acknowledged for providing us with his vast local expertise. Collection of specimens was conducted in accordance with national and provincial guidelines and permits. All student colleagues are acknowledged for their help in and commitment to the fieldwork. We also thank S. Nachtigall and C. Wolff for their help with the DNA work and K. Preußer for the habitus images shown in Fig. 1. T. Stadler is acknowledged for helpful comments on TreePar. The referees A. Weigand and T. von Rintelen provided valuable comments and helped improve the manuscript. This work was supported by German Research Foundation (DFG) grants WI 1902/13-1 and AL 1076/9-1 to T. Wilke and C. Albrecht, respectively.

Edited by: B. Wagner

\section{References}

Albrecht, C. and Wilke, T.: Ancient Lake Ohrid: biodiversity and evolution, Hydrobiologia, 615, 103-140, doi:10.1007/s10750008-9558-y, 2008.

Albrecht, C., Trajanovski, S., Kuhn, K., Streit, B., and Wilke, T.: Rapid evolution of an ancient lake species flock: freshwater limpets (Gastropoda: Ancylidae) in the Balkan Lake Ohrid, Org. Divers. Evol., 6, 294-307, doi:10.1016/j.ode.2005.12.003, 2006.

Albrecht, C., Hauffe, T., Schreiber, K., Trajanovski, S., and Wilke, T.: Mollusc biodiversity and endemism in the potential ancient Lake Trichonis, Greece, Malacologia, 51, 357-375, doi:10.4002/040.051.0209, 2009.
Albrecht, C., Vogel, H., Hauffe, T., and Wilke, T.: Sediment core fossils in ancient Lake Ohrid: testing for faunal change since the Last Interglacial, Biogeosciences, 7, 3435-3446, doi:10.5194/bg-7-3435-2010, 2010.

Albrecht, C., Föller, K., Clewing, C., Hauffe, T., and Wilke, T.: Invaders versus endemics: alien gastropod species in ancient Lake Ohrid, Hydrobiologia, 739, 163-174, doi:10.1007/s10750-0131724-1, 2014.

Brooks, J. L.: Speciation in ancient lakes, Q. Rev. Biol., 25, 30-60, 131-176, 1950.

Cohen, A. S., Stone, J. R., Beuning, K. R. M., Park, L. E., Reinthal, P. N., Dettman, D., Scholz, C. A., Johnson, T. C., King, J. W., Talbot, M. R., Brown, E. T., and Ivory, S. J.: Ecological consequences of early Late Pleistocene megadroughts in tropial Africa, Proc. Natl. Acad. Sci. USA, 104, 16422-16427, 2007.

Cristescu, M. E., Adamowicz, S. J., Vaillant, J. J., and Haffner, G. D.: Ancient lakes revisited: from the ecology to the genetics of speciation, Mol. Ecol., 19, 4837-4851, doi:10.1111/j.1365294X.2010.04832.x, 2010.

Cvetkoska, A., Jovanovska, E., Francke, A., Tofilovska, S., Vogel, H., Levkov, Z., Donders, T. H., Wagner, B., and WagnerCremer, F.: Ecosystem regimes and responses in a coupled ancient lake system from MIS 5b to present: the diatom record of lakes Ohrid and Prespa, Biogeosciences Discuss., 12, 1505115086, doi:10.5194/bgd-12-15051-2015, 2015.

Drummond, A. J. and Rambaut, A.: BEAST: Bayesian evolutionary analysis by sampling trees, BMC Evol. Biol., 7, 214, doi:10.1186/1471-2148-7-214, 2007.

Falniowski, A. and Szarowska, M.: The genus Daphniola Radoman, 1973 (Caenogastropoda: Hydrobiidae) in the Peloponnese, Greece, Folia Malacol., 19, 131-137, doi:10.2478/v10125-0110020-9, 2011.

Falniowski, A., Szarowska, M., Glöer, P., and Pešic, V.: Molecules vs morphology in the taxonomy of the Radomaniola/Grossuana group of Balkan Rissooidea (Mollusca, Caenogastropoda), J. Conchol., 41, 19-36, 2012.

Folmer, O., Black, M., Hoeh, W., Lutz, R., and Vrijenhoek, R.: DNA primers for amplification of mitochondrial cytochrome $\mathrm{c}$ oxidase subunit I from diverse metazoan invertebrates, Mol. Mar. Biol. Biotechnol., 3, 294-299, 1994.

Francke, A., Wagner, B., Just, J., Leicher, N., Gromig, R., Baumgarten, H., Vogel, H., Lacey, J. H., Sadori, L., Wonik, T., Leng, M. J., Zanchetta, G., Sulpizio, R., and Giaccio, B.: Sedimentological processes and environmental variability at Lake Ohrid (Macedonia, Albania) between $640 \mathrm{ka}$ and present day, Biogeosciences Discuss., 12, 15111-15156, doi:10.5194/bgd-1215111-2015, 2015.

Gould, S. J. and Eldredge, N.: Punctuated equilibria: the tempo and mode of evolution reconsidered, Paleobiology, 3, 115-151, 1977.

Greenwood, P. H., Echelle, A. A., and Kornfield, I.: What is a species flock?, in Evolution of fish species flocks, edited by: Echelle, A. A. and Kornfield, I., Orono Press, University of Maine, 13-19, 1984.

Grummer, J. A., Bryson Jr., R. W., and Reeder, T. W.: Species delimitation using Bayes factors: simulations and application to the Sceloporus scalaris species group (Squamata: Phrynosomatidae), Syst. Biol., 63, 119-133, doi:10.1093/sysbio/syt069, 2014. 
Hall, T. A.: BioEdit: a user-friendly biological sequence alignment editor and analysis program for Windows 95/98/NT, Nucleic Acids Symp. Ser., 41, 95-98, 1999.

Hauffe, T., Albrecht, C., Schreiber, K., Birkhofer, K., Trajanovski, S., and Wilke, T.: Spatially explicit analysis of gastropod biodiversity in ancient Lake Ohrid, Biogeosciences, 8, 175-188, doi:10.5194/bg-8-175-2011, 2011.

Hauswald, A. K., Albrecht, C., and Wilke, T.: Testing two contrasting evolutionary patterns in ancient lakes: species flock versus species scatter in valvatid gastropods of Lake Ohrid, Hydrobiologia, 615, 169-179, 2008.

Hinderer, M. and Einsele, G.: The world's large lake basins as denudation-accumulation systems and implications for their lifetimes, J. Paleolimnol., 26, 355-372, doi:10.1023/A:1012651232541, 2001.

Ivanov, A. V., Gladkochub, D. P., Déverchère, J., and Ernst, R. E.: Introduction to special issue: geology of the Lake Baikal region, J. Asian Earth Sci., 62, 1-3, doi:10.1016/j.jseaes.2012.12.010, 2013.

Jovanovska, E., Cvetkoska, A., Hauffe, T., Levkov, Z., Wagner, B., Sulpizio, R., Francke, A., Albrecht, C., and Wilke, T.: Differential resilience of ancient sister lakes Ohrid and Prespa to environmental disturbances during the Late Pleistocene, Biogeosciences Discuss., 12, 16049-16079, doi:10.5194/bgd-1216049-2015, 2015.

Kilikowska, A., Wysocka, A., Burzyński, A., Kostoski, G., Rychlińska, J., and Sell, J.: Patterns of genetic differentiation and population history of endemic isopods (Asellidae) from ancient Lake Ohrid: combining allozyme and mtDNA data, Cent. Eur. J. Biol., 8, 854-875, doi:10.2478/s11535-013-0204-y, 2013.

Kroll, O., Hershler, R., Albrecht, C., Terrazas, E. M., Apaza, R., Fuentealba, C., Wolff, C., and Wilke, T.: The endemic gastropod fauna of Lake Titicaca: correlation between molecular evolution and hydrographic history, Ecol. Evol., 2, 1517-1530, doi:10.1002/ece3.280, 2012.

Lavenu, A.: Formation and geological evolution, in Lake Titicaca: a synthesis of limnological knowledge, edited by C. Dejoux and A. Iltis, pp. 3-15, Kluwer Academic Publishers, Dordrecht, 1992.

Leicher, N., Zanchetta, G., Sulpizio, R., Giaccio, B., Wagner, B., Nomade, S., Francke, A., and Del Carlo, P.: First tephrostratigraphic results of the DEEP site record from Lake Ohrid, Macedonia, Biogeosciences Discuss., 12, 15411-15460, doi:10.5194/bgd-12-15411-2015, 2015.

Levkov, Z. and Williams, D. M.: Checklist of diatoms (Bacillariophyta) from Lake Ohrid and Lake Prespa (Macedonia), and their watersheds, Phytotaxa, 45, 1-76, 2012.

Lézine, A. M., von Grafenstein, U., Andersen, N., Belmecheri, S., Bordon, A., Caron, B., Cazet, J. P., Erlenkeuser, H., Fouache, E., Grenier, C., Huntsman-Mapila, P., Hureau-Mazaudier, D., Manelli, D., Mazaud, A., Robert, C., Sulpizio, R., Tiercelin, J. J., Zanchetta, G., and Zeqollari, Z.: Lake Ohrid, Albania, provides an exceptional multi-proxy record of environmental changes during the last glacial-interglacial cycle, Palaeogeogr. Palaeoclimatol. Palaeoecol., 287, 116-127, doi:10.1016/j.palaeo.2010.01.016, 2010.

Lindhorst, K., Vogel, H., Krastel, S., Wagner, B., Hilgers, A., Zander, A., Schwenk, T., Wessels, M., and Daut, G.: Stratigraphic analysis of lake level fluctuations in Lake Ohrid: an integration of high resolution hydro-acoustic data and sediment cores, Biogeosciences, 7, 3531-3548, doi:10.5194/bg-7-3531-2010, 2010.

Lindhorst, K., Krastel, S., Reicherter, K., Stipp, M., Wagner, B. and Schwenk, T.: Sedimentary and tectonic evolution of Lake Ohrid (Macedonia/Albania), Basin Res., 27, 84-101, doi:10.1111/bre.12063, 2015.

Martens, K.: Speciation in ancient lakes, Trends Ecol. Evol., 12, 177-182, doi:10.1016/S0169-5347(97)01039-2, 1997.

Martens, K., Goddeeris, B. and Coulter, G. (Eds.): Speciation in ancient lakes, E. Schweitzerbart'sche Verlagsbuchhandlung, Stuttgart, 1994.

Matzinger, A., Spirkovski, Z., Patceva, S., and Wüest, A.: Sensitivity of ancient Lake Ohrid to local anthropogenic impacts and global warming, J. Great Lakes Res., 32, 158-179, doi:10.3394/0380-1330(2006)32[158:SOALOT]2.0.CO;2, 2006.

Morvan, C., Malard, F., Paradis, E., Lefébure, T., Konecny-Dupré, L., and Douady, C. J.: Timetree of Aselloidea reveals species diversification dynamics in groundwater, Syst. Biol., 62, 512-522, doi:10.1093/sysbio/syt015, 2013.

Newton, M. A. and Raftery, A. E.: Approximate Bayesian inference with the weighted likelihood bootstrap, J. R. Stat. Soc. B, 56, 348, 1994.

Pagel, M.: Inferring the historical patterns of biological evolution, Nature, 401, 877-884, 1999.

Palumbi, S. R., Martin, A., Romano, S., McMillan, W. O., Stice, L., and Grabowski, G.: The simple fool's guide to PCR, University of Hawaii, Honolulu, 1991.

Paradis, E., Claude, J., and Strimmer, K.: APE: analyses of phylogenetics and evolution in R language, Bioinformatics, 20, 289-290, doi:10.1093/bioinformatics/btg412, 2004.

Pennell, M. W., Harmon, L. J., and Uyeda, J. C.: Is there room for punctuated equilibrium in macroevolution?, Trends Ecol. Evol., 29, 23-32, doi:10.1016/j.tree.2013.07.004, 2014.

Pešić, V.: A new species of the water mite genus Hygrobates Koch, 1837 (Acari: Hydrachnidia: Hygrobatidae) from the ancient Lake Ohrid, Zootaxa, 3926, 287-295, doi:10.11646/zootaxa.3926.2.9, 2015.

Posada, D.: jModelTest: phylogenetic model averaging, Mol. Biol. Evol., 25, 1253-1256, doi:10.1093/molbev/msn083, 2008.

Purvis, A., Orme, C. D. L., Toomey, N. H., and Pearson, P. N.: Temporal patterns in diversification rates, in: Speciation and patterns of diversity, edited by: Butlin, R. K., Bridle, J. R., and Schulter, D., 278-300, Cambridge University Press, Cambridge, 2009.

Rabosky, D. L.: Extinction rates should not be estimated from molecular phylogenies, Evolution, 64, 1816-1824, doi:10.1111/j.1558-5646.2009.00926.x, 2010.

Radoman, P.: Hydrobioidea, a superfamily of Prosobranchia (Gastropoda). I. Systematics, Monographs Vol. 547, Department of Sciences No. 57, Serbian Academy of Sciences and Arts, Beograd, 1983.

Radoman, P.: Hydrobioidea, a superfamily of Prosobranchia (Gastropoda). II. Origin, zoogeography, evolution in the Balkans and Asia Minor, Monographs Vol. 1, Institute of Zoology No. 1, Faculty of Science - Department of Biology, Beograd, 1985.

Rambaut, A. and Drummond, A. J.: Tracer v. 1.5, available at: http:// tree.bio.ed.ac.uk/software (last access: 7 December 2015), 2007.

R Core Team: R: a language and environment for statistical computing. R Foundation for Statistical Computing, Vienna, Austria, 
available at: http://www.R-project.org (last access: 7 December 2015), 2015.

Reed, J. M., Cvetkoska, A., Levkov, Z., Vogel, H., and Wagner, B.: The last glacial-interglacial cycle in Lake Ohrid (Macedonia/Albania): testing diatom response to climate, Biogeosciences, 7, 3083-3094, doi:10.5194/bg-7-3083-2010, 2010.

Revell, L. J.: phytools: an R package for phylogenetic comparative biology (and other things), Methods Ecol. Evol., 3, 217-223, doi:10.1111/j.2041-210X.2011.00169.x, 2012.

Rossiter, A. and Kawanabe, H.: Ancient lakes: biodiversity, ecology and evolution, Academic Press, San Diego, 2000.

Salzburger, W., Mack, T., Verheyen, E., and Meyer, A.: Out of Tanganyika: genesis, explosive speciation, key-innovations and phylogeography of the haplochromine cichlid fishes, BMC Evol. Biol., 5, 17, doi:10.1186/1471-2148-5-17, 2005.

Salzburger, W., Van Bocxlaer, B., and Cohen, A. S.: Ecology and evolution of the African Great Lakes and their faunas, Annu. Rev. Ecol. Evol. Syst., 45, 519-545, doi:10.1146/annurev-ecolsys120213-091804, 2014.

Scheffer, M. and Carpenter, S. R.: Catastrophic regime shifts in ecosystems: linking theory to observation, Trends Ecol. Evol., 18, 648-656, doi:10.1016/j.tree.2003.09.002, 2003.

Scheffer, M., Carpenter, S., Foley, J. A., Folke, C., and Walker, B.: Catastrophic shifts in ecosystems, Nature, 413, 591-596, doi:10.1038/35098000, 2001.

Schluter, D.: The ecology of adaptive radiation, edited by: May, R. M. and Harvey, P. H., Oxford University Press, Oxford, 2000.

Scholz, C. A., Johnson, T. C., Cohen, A. S., King, J. W., Peck, J. A., Overpeck, J. T., Talbot, M. R., Brown, E. T., Kalindekafe, L., Amoako, P. Y. O., Lyons, R. P., Shanahan, T. M., Castañeda, I. S., Heil, C. W., Forman, S. L., McHargue, L. R., Beuning, K. R., Gomez, J., and Pierson, J.: East African megadroughts between 135 and 75 thousand years ago and bearing on earlymodern human origins, Proc. Natl. Acad. Sci. USA, 104, 1641621, doi:10.1073/pnas.0703874104, 2007.

Schön, I. and Martens, K.: Adaptive, pre-adaptive and non-adaptive components of radiations in ancient lakes: a review, Org. Divers. Evol., 4, 137-156, doi:10.1016/j.ode.2004.03.001, 2004.

Schreiber, K., Hauffe, T., Albrecht, C., and Wilke, T.: The role of barriers and gradients in differentiation processes of pyrgulinid microgastropods of Lake Ohrid, Hydrobiologia, 682, 6173, doi:10.1007/s10750-011-0864-4, 2012.

Schultheiß, R., Van Bocxlaer, B., Wilke, T., and Albrecht, C.: Old fossils-young species: evolutionary history of an endemic gastropod assemblage in Lake Malawi, Proc. R. Soc. London B, 276, 2837-2846, doi:10.1098/rspb.2009.0467, 2009.

Schultheiß, R., Wilke, T., Jørgensen, A., and Albrecht, C.: The birth of an endemic species flock: demographic history of the Bellamya group (Gastropoda, Viviparidae) in Lake Malawi, Biol. J. Linn. Soc., 102, 130-143, 2011.

Sherbakov, D. Y.: Molecular phylogenetic studies on the origin of biodiversity in Lake Baikal, Trends Ecol. Evol., 14, 92-95, doi:10.1016/S0169-5347(98)01543-2, 1999.

Slager, D. L., Battey, C. J., Bryson, R. W., Voelker, G., and Klicka, J.: A multilocus phylogeny of a major New World avian radiation: the Vireonidae, Mol. Phylogenet. Evol., 80, 95-104, doi:10.1016/j.ympev.2014.07.021, 2014.

Stadler, T.: Mammalian phylogeny reveals recent diversification rate shifts, Proc. Natl. Acad. Sci. USA, 108, 6187-6192, 2011.
Stadler, T.: TreePar: Estimating birth and death rates based on phylogenies, $\mathrm{R}$ package version 3.3, available at: http://CRAN. R-project.org/package $=$ TreePar (last access: 7 December 2015), 2015.

Stankovic, S.: The Balkan Lake Ohrid and its living world, Dr. W. Junk, The Hague, 1960.

Stocchino, G. A., Sluys, R., Deri, P., and Manconi, R.: Integrative taxonomy of a new species of planarian from the Lake Ohrid basin, including an analysis of biogeographical patterns in freshwater triclads from the Ohrid region (Platyhelminthes, Tricladida, Dugesiidae), Zookeys, 313, 25-43, doi:10.3897/zookeys.313.5363, 2013.

Suchard, M. A., Weiss, R. E., and Sinsheimer, J. S.: Bayesian selection of continuous-time Markov chain evolutionary models, Mol. Biol. Evol., 18, 1001-1013, doi:10.1093/oxfordjournals.molbev.a003872, 2001.

Sulpizio, R., Zanchetta, G., D’Orazio, M., Vogel, H., and Wagner, B.: Tephrostratigraphy and tephrochronology of lakes Ohrid and Prespa, Balkans, Biogeosciences, 7, 3273-3288, doi:10.5194/bg7-3273-2010, 2010.

Szarowska, M.: Molecular phylogeny, systematics and morphological character evolution in the Balkan Rissooidea (Caenogastropoda), Folia Malacol., 14, 99-168, doi:10.12657/folmal.014.014, 2006.

Szarowska, M., Grzmil, P., Falniowski, A. and Sirbu, I.: Grossuana codreanui (Grossu, 1946) and the phylogenetic relationships of the East Balkan genus Grossuana (Radoman, 1973) (Gastropoda: Rissooidea), Hydrobiologia, 579, 379-391, doi:10.1007/s10750006-0530-4, 2007.

Trajanovski, S., Albrecht, C., Schreiber, K., Schultheiß, R., Stadler, T., Benke, M., and Wilke, T.: Testing the spatial and temporal framework of speciation in an ancient lake species flock: the leech genus Dina (Hirudinea: Erpobdellidae) in Lake Ohrid, Biogeosciences, 7, 3387-3402, doi:10.5194/bg-7-3387-2010, 2010.

Van Bocxlaer, B., Damme, D. V., and Feibel, C. S.: Gradual versus punctuated equilibrium evolution in the Turkana Basin molluscs: evolutionary events or biological invasions?, Evolution, 62, 511520, doi:10.1111/j.1558-5646.2007.00296.x, 2008.

Wagner, B., Wilke, T., Krastel, S., Zanchetta, G., Sulpizio, R., Reicherter, K., Leng, M. J., Grazhdani, A., Trajanovski, S., Francke, A., Lindhorst, K., Levkov, Z., Cvetkoska, A., Reed, J. M., Zhang, X., Lacey, J. H., Wonik, T., Baumgarten, H., and Vogel, H.: The SCOPSCO drilling project recovers more than 1.2 million years of history from Lake Ohrid, Sci. Dril., 17, 19-29, doi:10.5194/sd-17-19-2014, 2014.

Wilke, T. and Davis, G. M.: Infraspecific mitochondrial sequence diversity in Hydrobia ulvae and Hydrobia ventrosa (Hydrobiidae: Rissooidea: Gastropoda): Do their different life histories affect biogeographic patterns and gene flow?, Biol. J. Linn. Soc., 70, 89-105, doi:10.1006/bijl.1999.0388, 2000.

Wilke, T., Davis, G. M., Falniowski, A., Giusti, F., Bodon, M., and Szarowska, M.: Molecular systematics of Hydrobiidae (Mollusca: Gastropoda: Rissooidea): testing monophyly and phylogenetic relationships, Proc. Acad. Nat. Sci. Philadelphia, 151, 1-21, doi:10.1635/0097-3157(2001)151[0001:MSOHMG]2.0.CO;2, 2001.

Wilke, T., Davis, G. M., Qiu, D., and Spear, R. C.: Extreme mitochondrial sequence diversity in the intermediate schistosomiasis 
host Oncomelania hupensis robertsoni: another case of ancestral polymorphism?, Malacologia, 48, 143-157, 2006.

Wilke, T., Albrecht, C., Anistratenko, V. V., Sahin, S. K., and Yildirim, Z.: Testing biogeographical hypotheses in space and time: faunal relationships of the putative ancient Lake Egirdir in Asia Minor, J. Biogeogr., 34, 1807-1821, doi:10.1111/j.13652699.2007.01727.x, 2007.

Wilke, T., Schultheiß, R., and Albrecht, C.: As time goes by: a simple fool's guide to molecular clock approaches in invertebrates, Am. Malacol. Bull., 27, 25-45, doi:10.4003/006.027.0203, 2009.

Wilke, T., Haase, M., Hershler, R., Liu, H.-P., Misof, B., and Ponder, W.: Pushing short DNA fragments to the limit: phylogenetic relationships of "hydrobioid" gastropods (Caenogastropoda: Rissooidea), Mol. Phylogenet. Evol., 66, 715-736, doi:10.1016/j.ympev.2012.10.025, 2013.

Wilson, A. B., Glaubrecht, M., and Meyer, A.: Ancient lakes as evolutionary reservoirs: evidence from the thalassoid gastropods of Lake Tanganyika, Proc. R. Soc. London B, 271, 529-536, doi:10.1098/rspb.2003.2624, 2004.
Wysocka, A., Kostoski, G., Kilikowska, A., Wróbel, B.. and Sell, J.: The Proasellus (Crustacea, Isopoda) species group, endemic to the Balkan Lake Ohrid: a case of ecological diversification?, Fundam. Appl. Limnol. / Arch. für Hydrobiol., 172, 301-313, doi:10.1127/1863-9135/2008/0172-0301, 2008.

Wysocka, A., Grabowski, M., Sworobowicz, L., Burzyński, A., Kilikowska, A., Kostoski, G.. and Sell, J.: A tale of time and depth: intralacustrine radiation in endemic Gammarus species flock from the ancient Lake Ohrid, Zool. J. Linn. Soc., 167, 345359, doi:10.1111/j.1096-3642.2012.00878.x, 2013.

Wysocka, A., Grabowski, M., Sworobowicz, L., Mamos, T., Burzyński, A., and Sell, J.: Origin of the Lake Ohrid gammarid species flock: ancient local phylogenetic lineage diversification, J. Biogeogr., 41, 1758-1768, doi:10.1111/jbi.12335, 2014.

Xia, X. and Xie, Z.: DAMBE: Data analysis in molecular biology and evolution, J. Hered., 92, 371-373, doi:10.1093/jhered/92.4.371, 2001.

Zhang, Z., Schwartz, S., Wagner, L.. and Miller, W.: A greedy algorithm for aligning DNA sequences, J. Comput. Biol., 7, 203-214, doi:10.1089/10665270050081478, 2000. 